\title{
Detection of Plants Leaf Diseases using Swarm Optimization Algorithms
}

Saud M.Abdul Razzaq
saud.maher88@gmail.com

Department of Computer Science, College of Computer Science and Mathematics, University of Mosul, Mosul, Iraq

Received on: 03/05/2021

Accepted on: 05/07/2021

\begin{abstract}
Classification is widely and largely used in data analysis, and pattern recognition. The data analysis aims to discover similarities between them and group them based on similarity into multiple classes. Artificial intelligence techniques are characterized by their great ability to classify objects and classify images. In this research, some artificial intelligence algorithms, represented by swarm optimization algorithms, were used to detect and classify plant diseases to healthy and unhealthy through images of different leaves of plants. Where plants are considered one of the most important organisms on this planet because of their important and fundamental role in the continuation of life and in achieving environmental balance, as well as in the economic side in many countries, and other benefits of high importance. These plants are apt to many different diseases. As a result of the technological development that the world witnessed in various areas of life, it was necessary to make use of it in the field of plant disease diagnosis, as many artificial intelligence techniques were employed in the discovery and diagnosis of plant diseases. In this paper, a new method is proposed to classify and distinguish a group of eight different plants to healthy and unhealthy based on the leaf images of these plants They are apples, cherries, grapes, peaches, peppers, potatoes, strawberries, and tomatoes using a hybrid optimization algorithm. In the first stage, the plant leaf images were collected and pre-processed to remove noise and improve contrast. In the second stage, the features were extracted based on the statistical feature extraction method, while in the third stage, the particle swarm (PSO) and chicken swarm optimization(CSO) algorithms were used to diagnose and classify plant diseases. Then these two algorithms were combined to produce a proposed hybrid algorithm called (PSO-CSO) hybrid method. The results obtained from these three algorithms were compared and the proposed method (PSO-CSO) obtained the best results compared to the two methods. Where the proposed method obtained in the first and second tests a diagnostic rate of $(96.9 \%)$ and $(98.18 \%)$, respectively.
\end{abstract}

Keyword: swarm intelligent techniques, Particle swarm optimization (PSO) and chicken swarm optimization (CSO), Feature extraction, Plant leaves images.

\section{Introduction}

Plants are one of the most important components of the world we live in. To be able to preserve this plant wealth, it is required to harness all the modern sciences we have come up with to preserve, improve and protect the most important types of plants whose durability plays a major role in daily life and the economy of many countries in general. The process of identifying diseases that affect plants in the past period relied on the human eye, led to difficulties and problems due to the difference in diagnosis from 
one person to another, which may lead to an inaccurate diagnosis of the condition [1]. In the current era we live in, which is the era of the digital revolution in all respects, the trend to employ digital development in our daily lives has become an urgent need. Therefore, employing all the findings of the digital revolution is needed in improving plant protection methods through various digital applications [2]. The applications of distinguishing diseases that affect plant leaves are one of the most important digital applications because of their great role. The early diagnosis of diseases help to avoid serious damage to plant wealth. Therefore, using automatic detection technology saves time and effort, and it leads to a more accurate diagnostic ratio as well [3]. The correct classification process for plant diseases will depend heavily on extracting the characteristics and features from the input images by processing the image and improving its quality. This facilitates the automatic identification of diseases by looking at the leaves of the plant, which contributes to reducing the cost resulting from the use of experts in diagnosing diseases [4][5].

Swarm intelligence algorithms are among the most important optimization strategies that depend on the intelligent behavior of swarms, in this paper we used the particle swarm (PSO) and chicken swarm optimization(CSO) algorithms are two of the swarm intelligence systems, the PSO algorithm simulates the social behavior of particles, which depends on the behavior of the swarm of particles to reach the optimal solution.

And the CSO algorithm is based on the collective behavior of the chicken flock group and uses this algorithm to solve improvement problems and get the best solutions.

To improve the identification, detection, and diagnosis of some plant leaves diseases. We combined between the behavior of this two methods PSO and CSO to produce a new proposed hybrid method called (PSO-CSO) hybrid method. And plant leaves diseases are either caused by insects, viruses, or bacteria that may infect leaves of plants that were studied and included. These plants have eight varieties: apples, cherries, grapes, peaches, peppers, potatoes, strawberries, and tomatoes.

\section{Related work}

A group of previous works on the application of different intelligent techniques in building digital systems will be viewed to detect and distinguish some of the diseases that affect different types of plants and the results achieved by these systems as follows:

In 2015, the two researchers suggested Muthukannan, K., Latha, P. a method to distinguish leaf diseases in India, as it is the country whose economy depends to a large extent on agriculture. The suggested method involved reading the image of the plant leaf and then subjecting it to a preparation process preceding the operations of cutting or segmentation. So the classification process represented by exposing the image to a Gaussian Filter for the purpose of removing unwanted stain information, and then Inputting the resulting image from this stage into the particle swarm algorithm for optimization. This method, it achieved a rating accuracy of $(90 \%)$ for discrimination and the classification of red spot disease (fungal disease) that affects cultivated leaves [6].

In 2016, the two researchers suggested Francis, J., Anoop, B. K. a method to segmentation technique for disease detection was applied to pepper leaves. The technique includes green pixel masking and threshold-based segmentation. This method was conducted to detect diseases such as raspberry spot and rapid wilt disease. The 
GLCM and neural network features were also used to classify pepper leaf disease. This work presented an evaluation study of the systems for detecting diseases in plants, without addressing the efficiency ratios or the quality of work [7].

In 2017 Prakash, R. M.et al. they have proposed a method to segment the disease region from an RGB image by applying color transformation and pooling of means $\mathrm{k}$. Where the experiment was conducted on citrus leaves to distinguish normal and abnormal leaves. Also, texture features were extracted using gray-level simultaneous presence matrix (GLCM) with SVM algorithm. The researcher did not discuss the efficiency rate for the work that has been accomplished [8].

In 2017, the two researchers suggested Madiwalar, S. C., Wyawahare, M. V. a method to use YcbCr color-based segmentation to detect mango leaf diseases. The experiment also used SVM and Minimum Distance Classifier (MDC) to classify diseases such as anthracnose and leaf spot. In addition, three different types of features such as color, GLCM, and Gabor features were extracted to compare the performance of SVM and MDC in mango leaf disease classification. The results gave a classification accuracy of $79.16 \%$ and $83.34 \%$ for the minimum distance classifier and the supporting vector machine respectively on a database of 86 images [9].

In 2019 the two researchers suggested Chanda, M., Biswas, M. an approach to distinguish five types of diseases affecting plant leaves in India Where a diffusion algorithm was used Back Propagation Algorithm for Neural Network Training. Then, they used the optimization algorithm for the PSO (Particle Swarm) Optimization to improve network weights and it was found that the proposed method achieved a percentage of discrimination that reached $(96.72 \%)$ [4].

In 2019, Singh, V. propose a method to divide and classify the disease-infected Litmus leaf images using the particle swarm improvement algorithm based on the minimum distance (Euclidean distance), where the method obtained an accuracy rate of $(98 \%)[10]$.

In 2019, researchers Kalavala, s.et al. proposed an effective classification system for plant disease detection. Viral, fungal and bacterial diseases called vital diseases were identified and classified. The images are initialized using major image processing techniques. The segmentation is done by k-mean, and GLCM is used to extract features from the images. The kurtosis, RMS, standard deviation, etc. are determined. Classification is performed by SVM and GUI with an accuracy rate of 90\%. [11].

In 2020 Chaudhary, A.et al. A new approach has propos to distinguish diseases that affect some important vegetables such as potatoes, Tomatoes, onions, beets, cabbage, celery, hot peppers, etc. The so-called optimization algorithm for the Unified Particle Swarm has been proposed, depending on EnsPSO (Ensemble Particle Swarm Optimization) several methods. These methods are Vote selection method, which combines forecasts from logistics Naive Bayse Algorithm and Simple Logistics. This method has recorded a classification accuracy of (84\%), while the proposed method EnsPSO scored a rating accuracy up to (96\%) CFS (Correlation based Feature Selection) [12].

\section{Methodology}

In our proposed method, related work were at first studied. The next step of this research is to work on the application and development of the proposed system method, so that the results are then evaluated and compared. 


\subsection{Dataset}

The plant image database for the work was obtained from the Kaggle website and consisted of 1475 images for the training and testing operations. They were divided as follows: 1000 images to implement a (binary classification)the first test for eight types of plants, which are apples, cherries, peaches, grapes, potatoes, tomatoes, strawberries, and peppers. Taking a satisfactory condition for the leaves for each type of plant, 775 images were adopted to train the system and 225 images to test the system to distinguish the images of plants into either healthy or infected that were entered. Figure (1) following shows Images of leaves for the database for the first test.
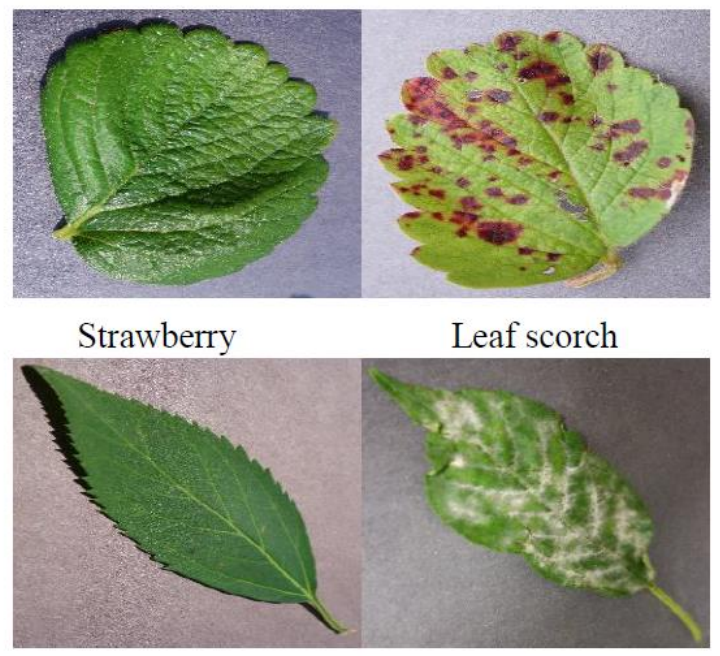

Cherry

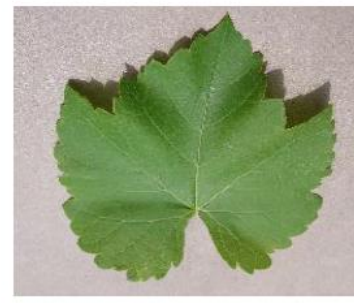

Grape

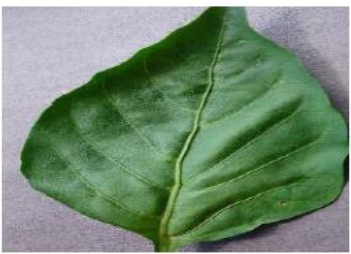

Pepper
Powdery Mildew

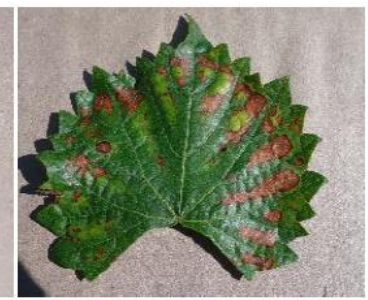

Black Measles

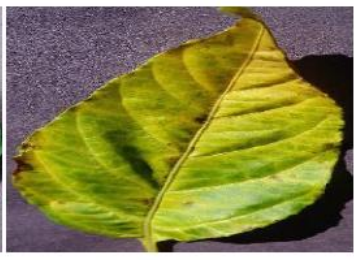

Bacterial spot

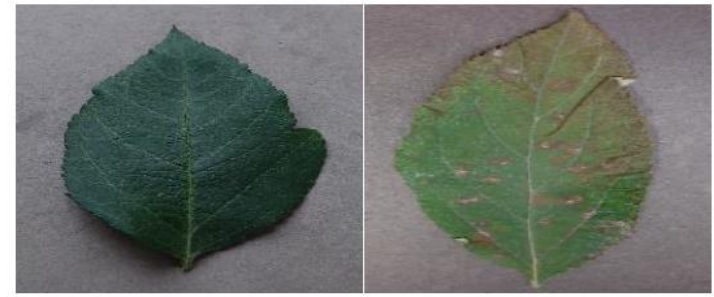

Apple

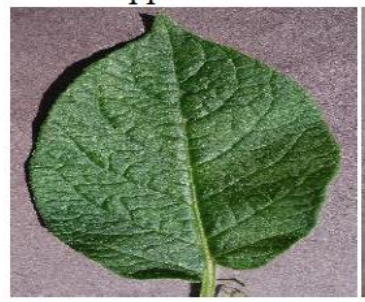

Potato

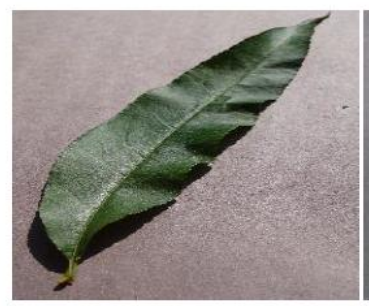

Peach

Apple rust

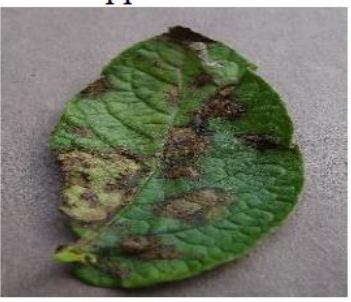

Late blight

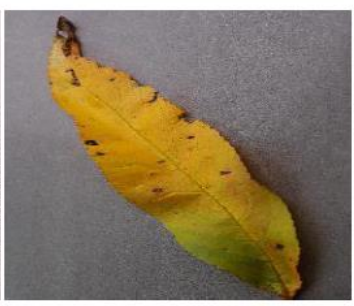

Bacterial spot

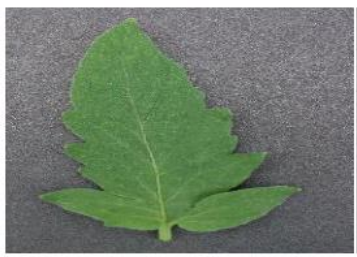

Tomato

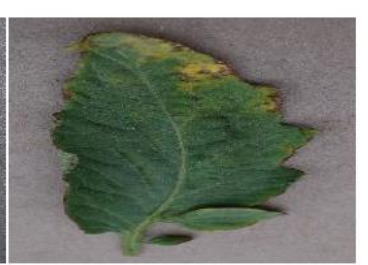

Early blight

Figure 1. Images of leaves for the database for the first test.

As for the second test, 475 images to implement a (multi-classification) test for tomato, potato plants and the common diseases between the two plants, which are leaf blight disease and early blight disease respectively. 350 images were used to train the system and 125 to test the system to distinguish and diagnose the images introduced into natural plant leaf for potato and tomato plants as well as plant leaf affected by leaf blight disease in addition to early blight disease Where Figure (2) the following shows Images of leaves for the database for the second test. 


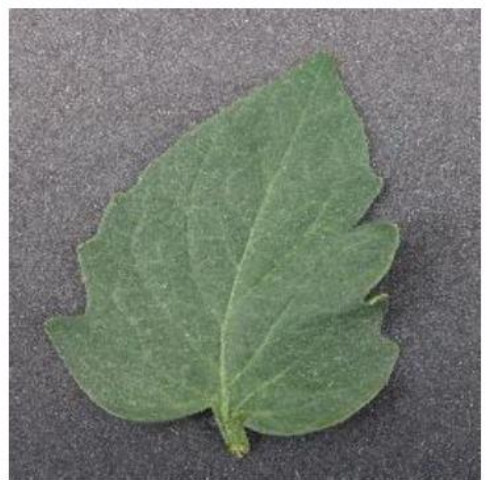

Tomato healthy

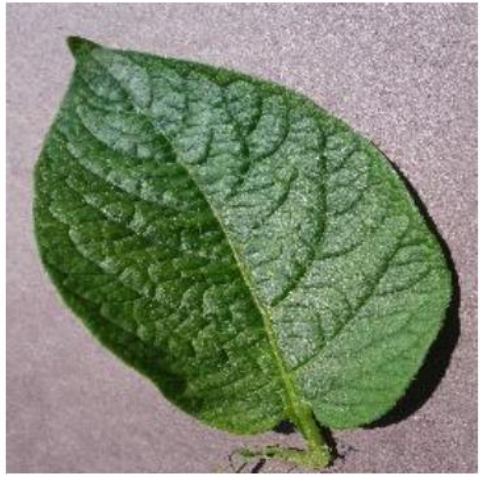

Potato healthy

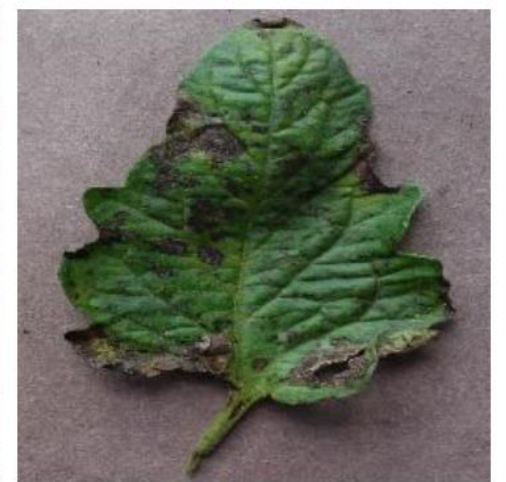

Tomato Early blight

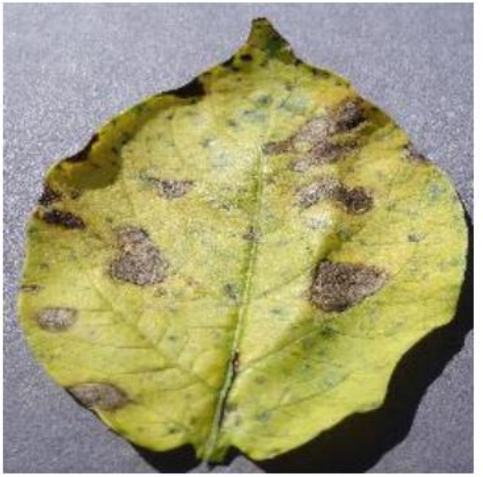

Potato Early blight

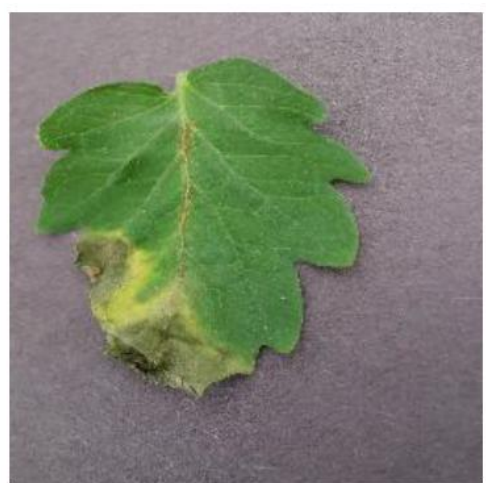

Tomato Late blight

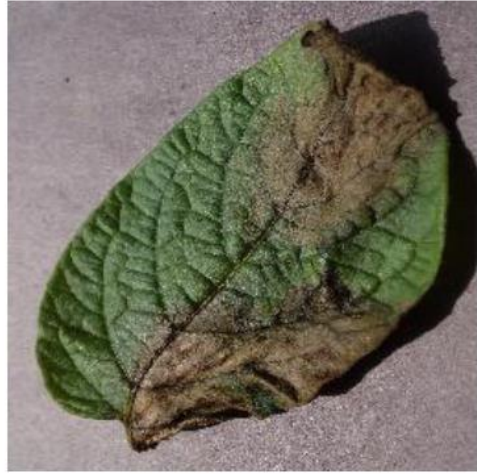

Potato Late blight

Figure 2. Images of leaves for the database for the second test.

\subsection{Image Pre-processing}

$\mathrm{T}$ The process of image processing is of great importance in extracting features from images and correct the diagnosis of the pathological condition of the paper. The process of image processing in our method is done by segmenting the image and getting the part of the sheet from the image and isolates it from the background based on color values and create a binary mask image using the Color Threshold application in Matlab. and then we converted the image from RGB to gray This is because gray-level images are easier to process compared to color images. and then improve the image with the histogram filter, which makes the image preprocessed clearer and more convenient to work with. Figure 3. The process of image segmentation and conversion of a color image to gray level. 


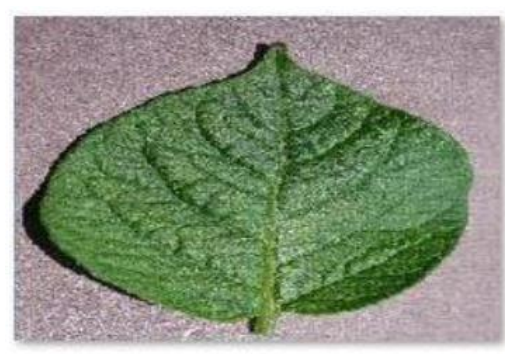

input image

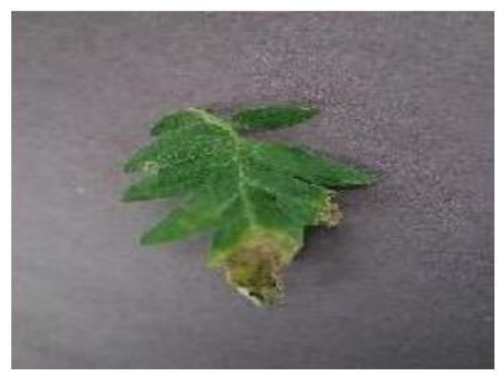

input image

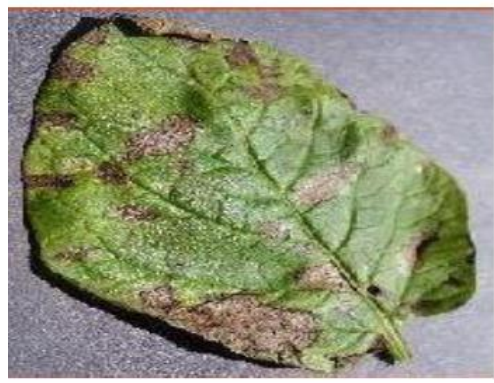

input image

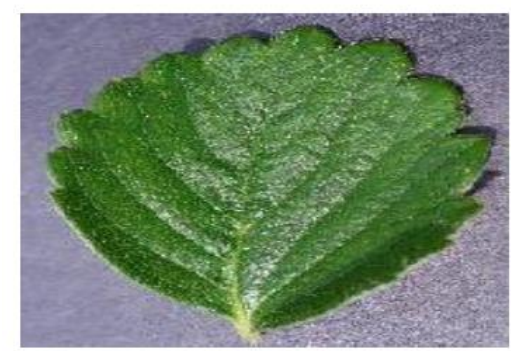

input image

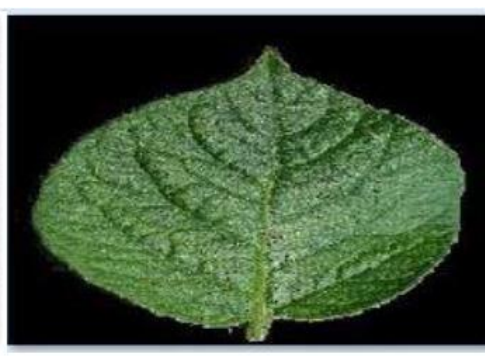

segment image

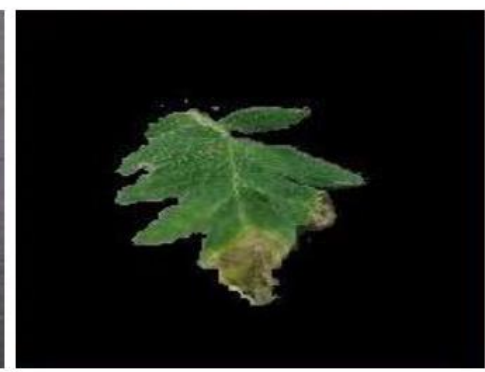

segment image

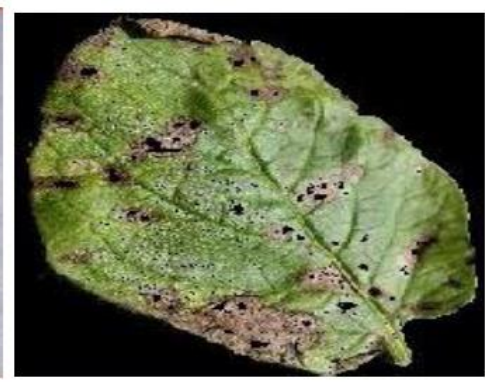

segment image

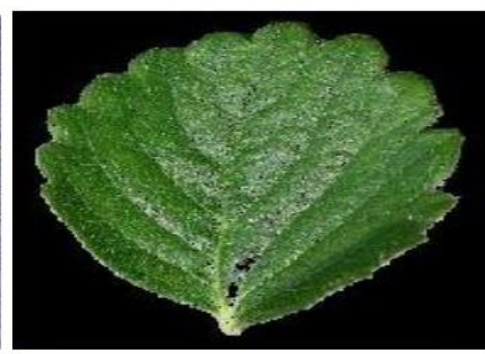

segment image

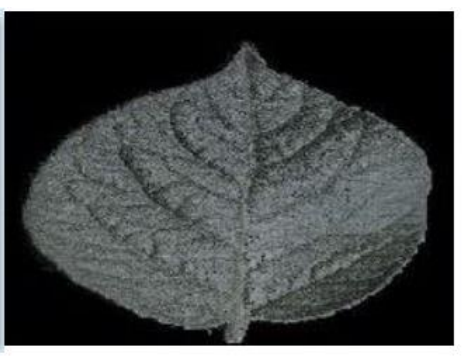

convert image to gray

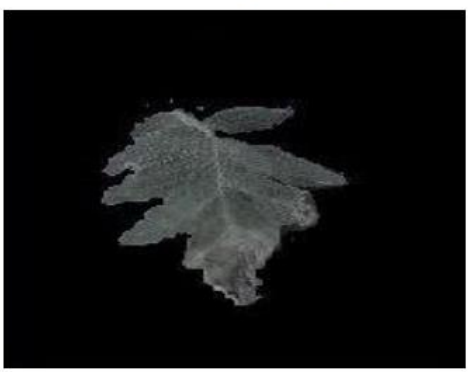

convert image to gray

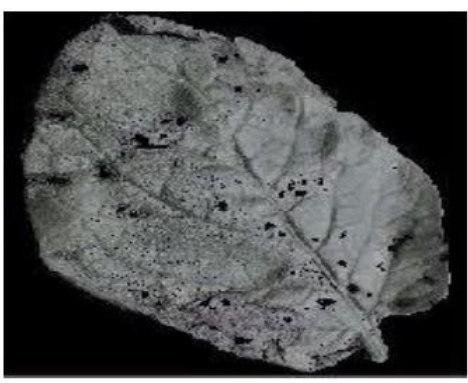

convert image to gray

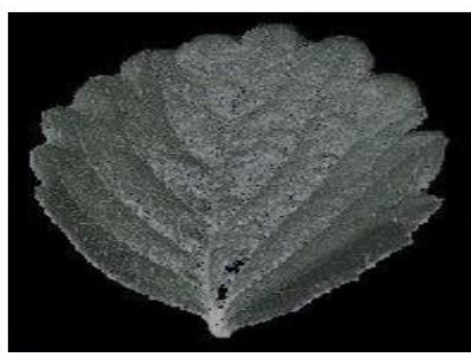

convert image to gray

Figure 3. Segmentation for image and Convert color image to gray level.

\subsection{Feature extraction}

The process of extracting properties is the cornerstone of an image processing system. That's where this process describes the image entering the system with a set of values that represent a specific feature, or a group of features that will determine the image processing process, whether it is a diagnosis, classification, or Identification, clustering, distinction, depending on the purpose of the intended system.

In this work, we used the Statistical Feature Extraction method. Where the graylevel co-occurrence matrix (GLCM) is first found, through which a number of texture features of the plant leaf cut from the background are found after converting it to gray level and they are:- Contrast, correlation, energy, homogeneity, entropy. The following 
statistical color features were also found: -RMS, mean, Skewness, standard deviation, variance, smoothness.

Features are extracted using the following equations from equation(1)to equation (11) [13] [14]:-

(1) Contrast is the measurement of the difference between the brightness of objects and other objects

It is calculated by the following equation:-

Contrast $=\sum(\mathrm{i}, \mathrm{j})^{2} \mathrm{q}(\mathrm{i}, \mathrm{j})$

(2) Correlation is a measure of the degree and type of relationship between adjacent pixels:-

Correlation $=\frac{\sum_{i=0}^{m-1} \sum_{j=0}^{m-1}\left(\mathrm{i}-\mathrm{n}_{\mathrm{i}}\right)\left(\mathrm{j}-\mathrm{n}_{\mathrm{j}}\right) \mathrm{q}(\mathrm{i}, \mathrm{j})}{\sigma i \sigma}$

(3) Energy is the sum of the squared elements in the gray-level co-occurrence of an array:-

Energy $=\sum \sum \mathrm{q}(\mathrm{i}, \mathrm{j})^{2}$

(4) Homogeneity is the convergence of the distribution of elements in GLCM:-

Homogeneity $=\sum_{i, j} \frac{q(i, j)}{1+|j-i|}$

(5) Entropy a statistical measure of randomness to distinguish the texture of the input image:-

Entropy $=-\sum \sum q(i, j) \log q(i, j)$

(6) RMS is the measure of the root mean square value of the image:-

RMS: $\quad X r m s=\sqrt{\frac{1}{m} \sum_{j=1}^{m}|y j|^{2}}$

(7) Mean is a measure of the average value of the density of pixels present in an area:-

Mean: $\quad M j=\sum_{m}^{i=1} \frac{1}{m} p j i$

(8) Skewness is a measure of the inconsistency in a statistical distribution:-

Skewness: $\quad S j=\sqrt[3]{\frac{1}{m} \sum_{m}^{i=1}(p j i-m j)^{3}}$

(9) Standard deviation is a measure of how much gray levels differ from their mean:-

Standard Deviation (STD): $\quad \sigma j=\sqrt{\frac{1}{m} \sum_{m}^{i=1}(p j i-m j)^{2}}$

(10) Variance is a measure of the contrast value of an image:-

Variance: $\sigma^{2}=\frac{1}{q} \sum_{i=1}^{a}(y i-m)^{2}$

(11) Smoothness is a measure of the relative smoothness of density in an area:-

Smoothness: $Q=1-\frac{1}{1+\sigma^{2}}$

Where:-

$\mathrm{q}$ is the number of gray-level iteration matrices in the GLCM. 
Y represents the incoming signal.

$\sigma$ represents the difference(Variance).

Pij represents the element $(\mathrm{i}, \mathrm{j})$ of the GLCM matrix.

$\mathrm{M}$ stands for mean.

$\sigma$ represents the standard deviation of the image.

And to ease the manipulation of plant disease images these features that were extracted are used in implementing the swarm optimization algorithms used in this work.

\subsection{Particle Swarm Optimization}

The PSO algorithm is an algorithm that simulates the social behavior of birds that was invented by both scientists (Kennedy and Eberhardt). It is considered one of the algorithms that are not subject to supervision and also this algorithm depends on the swarm of particles to discover and reach the solution across the search space. Each of these particles represents a proposed solution to the optimization problem [10] [15].

In PSO, the initialization process for a set of possible solutions is done randomly, and the search process is carried out repeatedly to reach the best solution by updating the population and parameters in each iteration [16]. There are three important parameters in PSO that serve to achieve diversification, condensation, and equilibrium, which are societal parameters (c1 and c2) and particle velocity (v). And Inertia Weight (w). Also, the particles are speed-bound within the range [vmin, vmax], which ensures that the particle does not leave the specified search area The idea of making the particle swarm algorithm is based on initializing the particles randomly and then calculating the fitness value for each particle, then comparing the fitness value of the particle with pbest, which represents the largest fitness value previously registered to it. pbest with gbest, which represents the best global or general fitness recorded for the swarm, then we calculate the particle velocity (eqn.12) and then update the particle position (eqn.13) and figure (4) shows how the PSO algorithm works. [17].

The velocity ( $\mathrm{Vi}$ ) and position (Xi) of each particle is changed and modified to reach the optimal solution by using the following equation(12) and equation (13) [16]:-

$$
\begin{aligned}
& V_{i, j}^{k+1}=w \times V_{i, j}^{k}+c 1 \times r 1 \times\left(\text { Pbest }_{i, j}^{k}-X_{i, j}^{k}\right)+c 2 \times r 2 \times\left(\text { Gbest }_{i, j}^{k}-X_{i, j}^{k}\right) \\
& X_{i, j}^{k+1}=X_{i, j}^{k}+V_{i, j}^{k+1}
\end{aligned}
$$

Where

$V_{i, j}^{k}$ represents the particle velocity .

$X_{i, j}{ }^{k}$ the current position of the particle.

$P$ best ${ }_{i, j}{ }^{k}$ Represents the best fitness value that the item has received.

Gbest $_{i, j}{ }^{k}$ Best global Fitness.

$\operatorname{Rand}()$ a random number that falls within the range $(0,1)$.

Figure (4) show the flowchart of Particle Swarm Optimization[17]. 


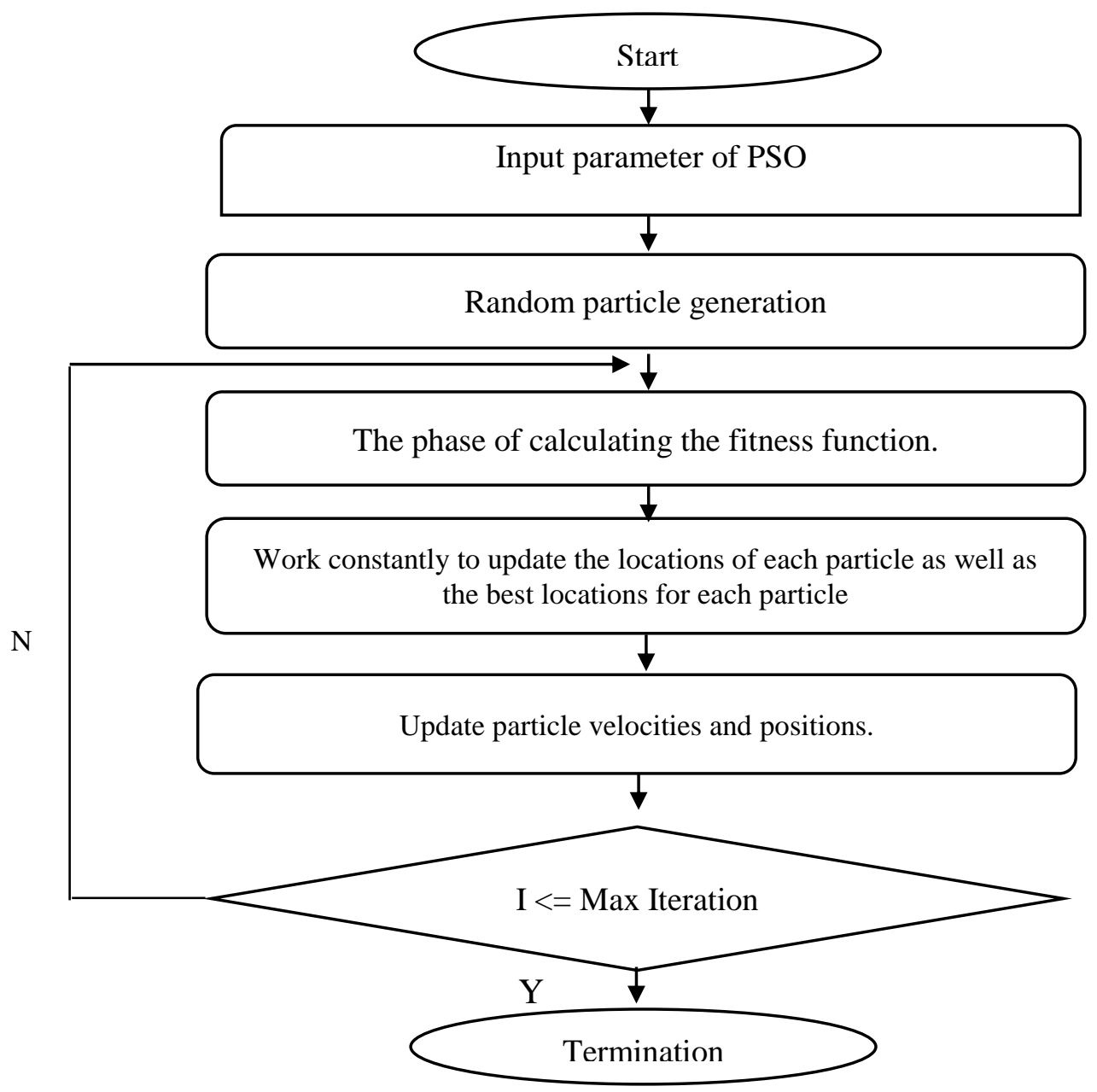

Figure 4. Diagram of Particle Swarm Optimization

\subsection{Chicken Swarm Optimization}

CSO is a modern stochastic optimization algorithm that is considered an intelligent swarm algorithm that solves the overall optimization problem by simulating the hierarchical arrangement and behavior of individuals within a group of the chicken swarm. In the chicken flock algorithm (CSO), the search process is repeatedly performed to arrive at the best solution by updating the population and parameters in each iteration[18] .In the chicken flock group, it will be divided into a number of subgroups, and each group will contain one rooster leading this group with some of its chickens in addition to many chicks, and the rooster is the predominant in this group, and its location is determined by their roosters as well[19].

Chicks depend on the mother hens in the group. The hierarchy in the flock of chickens is a very important factor, as the importance and role of each element within the same group is determined by the fitness values of the individual, the idea of the chicken flock algorithm is based on the consideration that roosters are the highest in fitness, then chickens. Then the chicks will be the weakest among them. Here it is assumed that $\mathrm{R}$ represents the number of roosters, $\mathrm{H}$ represents the number of hens, $\mathrm{C}$ represents the number of chicks, and $M$ represents the mother hens. The hierarchy is based on $(\mathrm{G})$ which represents a certain time period as these states are only updated every several time steps $(G)$ 
The steps of the chicken flock algorithm can be summarized as follows:-

(1) initialization of a flock of chickens, which includes the creation of the initial parameters of the algorithm and the setting of the maximum number of iterations and for the hierarchy $\mathrm{G}$

(2) Calculating the fitness value of each individual in a flock of chickens and then comparing it with his best recorded fitness.

(3) The roles of individuals within the swarm are updated by the condition $\bmod (\mathrm{t}, \mathrm{G})=1$, where $t$ represents the current iteration number. If the condition is met, move to step (4).

(4) Arrange chickens in ascending order based on their fitness values

(5) The status of roosters, hens and chicks is updated using equations (14) to (19) respectively and assesses the fitness of individuals.

(6) Evaluate new solutions.

If the new solutions are better than the previous ones, we update the solutions and adopt the best solution.

(7) The condition for stopping will be either when the required solution is reached or the number of pre-determined cycles has expired, otherwise I will go to step 4. [20][21].

Locations for individuals within the group are defined; the following equations are used as given in Eqs. (14) to (19),[20][21]:-

Equations for the movement of rooster:

$\mathrm{X}_{\mathrm{i}, \mathrm{j}}^{\mathrm{t}+1}=\mathrm{X}_{\mathrm{i}, \mathrm{j}}^{\mathrm{t}} *\left(1+\operatorname{Rand}\left(0, \sigma^{2}\right)\right)$

$\sigma^{2}=\left\{\begin{array}{l}(14) \\ 1, \text { if } f i \leq f k \\ \exp \frac{(f k-f i)}{|f i|+\varepsilon}, \text { otherwise } k \in[1, N], k \neq i\end{array}\right.$

Where

$X_{i, j}{ }^{(t)}$ current cock position., i represents the rooster., $\mathrm{t}$ number of cycles., $\sigma 2$ standard deviation., $f_{i}$ Fitness the rest of the corresponding items., $f_{k}$ fitness of a rooster that is chosen at random from a group of roosters., $\varepsilon$ is used to avoid the zero division error., $\mathrm{K}$ index rooster.

Chicken movement equations:

$$
\begin{aligned}
& \mathrm{X}_{\mathrm{i}, \mathrm{j}}^{\mathrm{t}+1}=\mathrm{X}_{\mathrm{i}, \mathrm{j}}^{\mathrm{t}}+\mathrm{C} 1 * \operatorname{Rand}\left(\mathrm{X}_{\mathrm{r} 1, \mathrm{j}}^{\mathrm{t}}-\mathrm{X}_{\mathrm{i}, \mathrm{j}}^{\mathrm{t}}\right)+\mathrm{C} 2 * \operatorname{Rand}\left(\mathrm{X}_{\mathrm{r} 2, \mathrm{j}}^{\mathrm{t}}-\mathrm{X}_{\mathrm{i}, \mathrm{j}}^{\mathrm{t}}\right) \\
& \mathrm{C} 1=\exp ((\mathrm{fi}-\mathrm{fr} 1) /(\operatorname{abs}(\mathrm{fi})+\varepsilon)) \\
& \mathrm{C} 2=\exp ((\mathrm{fr} 2-\mathrm{fi}))
\end{aligned}
$$

Where

$X_{i, j}{ }^{(t)}$ Hen's current position $\mathrm{Xi,j}(\mathrm{t}) .$, Rand is a regular random number between $(0$ 1)., $\mathrm{Xr1}, \mathrm{j}(\mathrm{t})$ The location of the group's rooster and his chickens., $\mathrm{Xr} 2, \mathrm{j}(\mathrm{t})$ The position of roosters or chickens chosen at random from the remaining elements with the condition $\mathrm{r} 1 \neq \mathrm{r} 2$., $f_{i}$ Fitness for group members., $\mathrm{f} r 1$ Cock Fitness Group., $\mathrm{f} r 2$ fitness of other rooster or chicken., r1 index your group.,r2 The index of the other rooster or hen, which is chosen at random $\neq \mathrm{r} 2 \mathrm{r} 1$

The equations for movement of chicks:

$$
\mathrm{X}_{\mathrm{i}, \mathrm{j}}^{\mathrm{t}+1}=\mathrm{X}_{\mathrm{i}, \mathrm{j}}^{\mathrm{t}}+\mathrm{FL}+\left(\mathrm{X}_{\mathrm{m}, \mathrm{j}}^{\mathrm{t}}-X_{i, j}^{t}\right)
$$

Where

$X_{i, j}{ }^{(t)}$ chicks position., $X_{m, j}{ }^{(t)}$ The position of the mother hen.,FL Chicks' correlation degree with their mothers 
And figure (5) show the Flowchart of chicken Swarm Optimization[24].

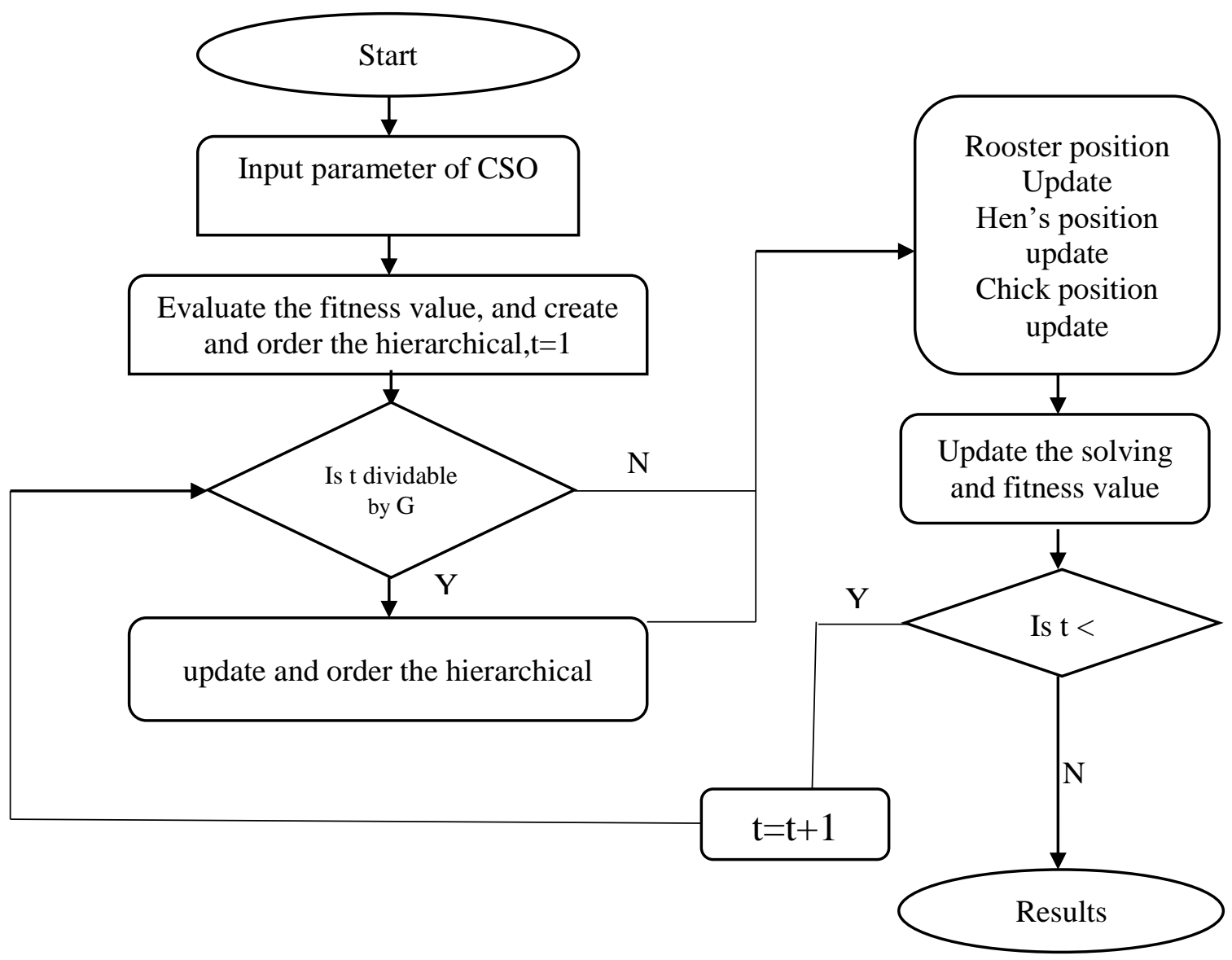

Figure 5. Flowchart of chicken Swarm Optimization.

\subsection{The proposed system design}

Swarm algorithms are considered one of the modern smart technologies in the field of artificial intelligence, which has a wide range of technical applications, as it is the ideal solution to multi-dimensional problems that help in approaching and improving the likelihood of reaching an optimal solution.

Swarm intelligence is an algorithm based on intelligence made up of a generation of intelligent agents and is inspired by the socialite demeanor of animals from the real world [22].

These algorithms mimic the mechanics of information exchange, sharing, and learning between swarm animals in the natural environment. What these algorithms have in common is that they all produce a good quality solution after a number of cycles. For this, it has attracted the interest of researchers because it is capable of Balancing the convergence rate and the quality of the solution [23].

As for the swarm algorithms used in this research, they include particle swarm optimization algorithm PSO and chicken swarm optimization algorithm CSO. To achieve better results and some kind of balance, and improving to obtain better results. And to improve the detection and classification, The two algorithms were hybridized together In order to get the best ratio For the accuracy of detection and classification of diseases that affect the types of eight plants that used in our current research Where Figure (6) the following diagram shows the proposed method of work. 


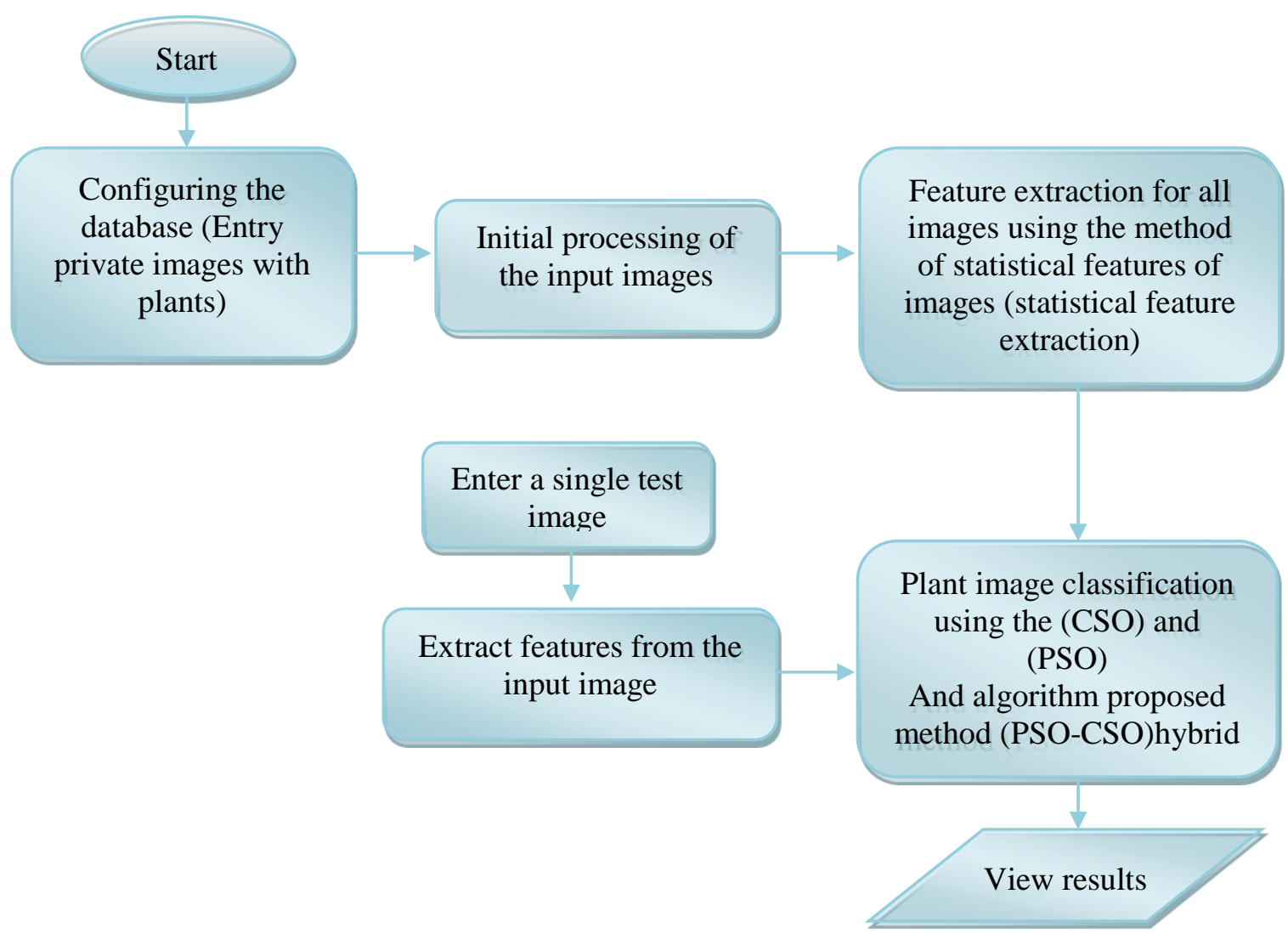

Figure 6. block diagram of the work.

The algorithm resulting from hybridization between (PSO) and (CSO) was named the proposed hybrid method (PSO-CSO), which is an algorithm resulting from the process of merging and hybridization between (PSO) and (CSO) algorithms, where the hybridization process depends on the way the (CSO) algorithm works ) in all its steps, but with changing the equations for updating and finding the positions of the cocks in the algorithm represented by equation (14) and equation (15) respectively, and using instead of taking the equation of velocity (Vi) and position (Xi) in the (PSO) algorithm represented by equation (12) and equation (13) respectively and as shown below:

$\mathrm{V}_{\mathrm{i}, \mathrm{j}}^{\mathrm{k}+1}=\mathrm{w} \times \mathrm{V}_{\mathrm{i}, \mathrm{j}}^{\mathrm{k}}+\mathrm{c} 1 \times \mathrm{r} 1 \times\left(\mathrm{Pbest}_{\mathrm{i}, \mathrm{j}}^{\mathrm{k}}-\mathrm{X}_{\mathrm{i}, \mathrm{j}}^{\mathrm{k}}\right)+\mathrm{c} 2 \times \mathrm{r} 2 \times\left(\right.$ Gbest $\left._{\mathrm{i}, \mathrm{j}}^{\mathrm{k}}-\mathrm{X}_{\mathrm{i}, \mathrm{j}}^{\mathrm{k}}\right)$

$X_{i, j}^{k+1}=X_{i, j}^{k}+V_{i, j}^{k+1}$

And using it as an alternative to the rooster position movement equations in the CSO algorithm shown below:-

$\mathrm{X}_{\mathrm{i}, \mathrm{j}}^{\mathrm{t}+1}=\mathrm{X}_{\mathrm{i}, \mathrm{j}}^{\mathrm{t}} *\left(1+\operatorname{Rand}\left(0, \sigma^{2}\right)\right)$

$\sigma^{2}=\left\{\begin{array}{l}1, \text { if } f i \leq f k \\ \exp \frac{(f k-f i)}{|f i|+\varepsilon}, \text { otherwise } \quad k \in[1, N], k \neq i\end{array}\right.$

Where Figure (7) the following shows the proposed hybrid method. 


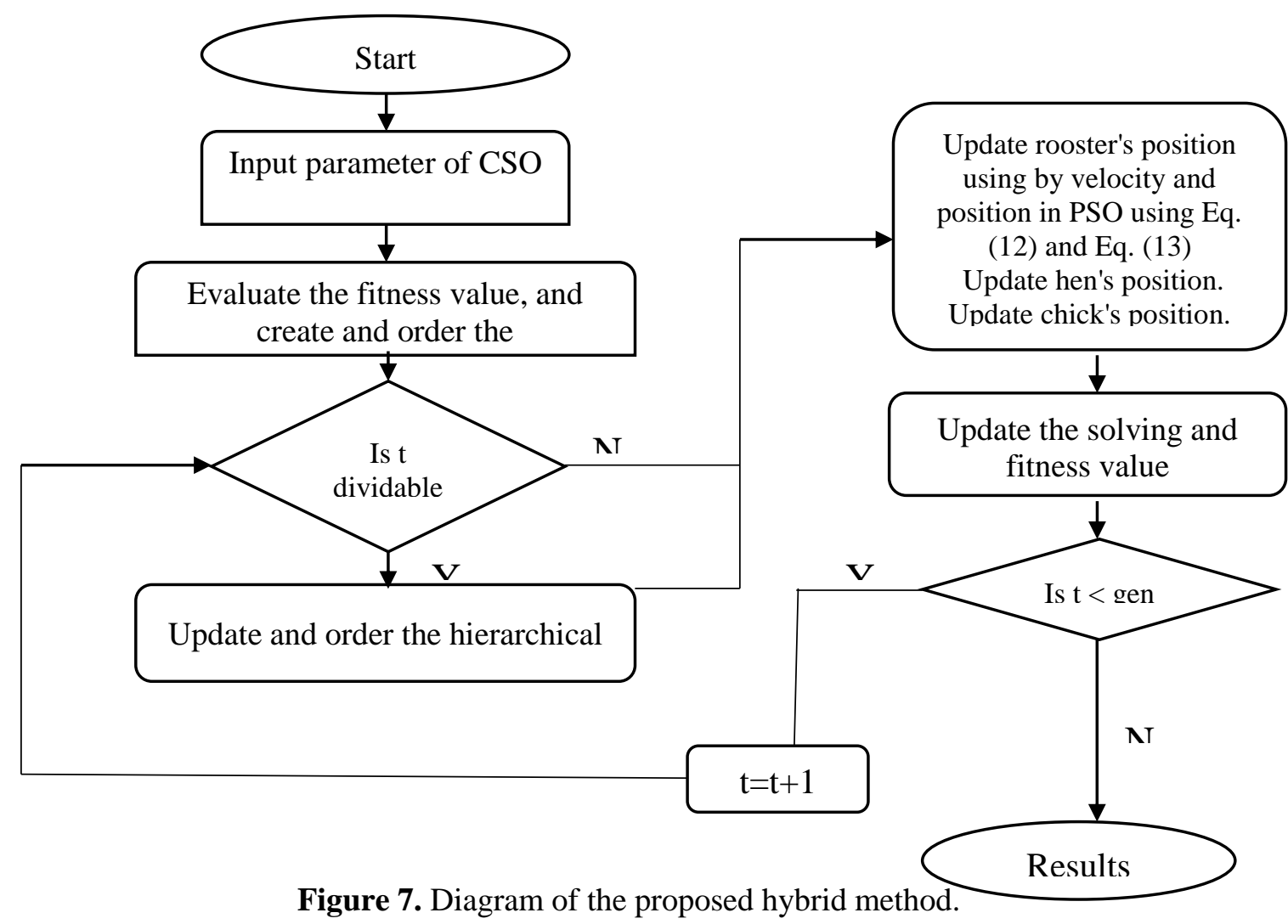

\section{Training Mode}

In this phase, Work was done on training the particle flock and chicken flock algorithm, as well as the proposed method (PSO -CSO). By inserting a matrix of statistical features extracted from the training images of the input plants images until reaching the stability of the algorithm. And classification aids in the recognition process of each type of leaf based on the characteristics extracted from the image. This is done using the criterion of minimum distance based on Euclidean distance [3].

After training the algorithms, a matrix of statistical features of the test images is entered on the PSO, CSO method and on the new method (PSO-CSO) hybrid method and conduct the test and then show the classification results for each algorithm.

\subsection{Experiments and Results}

The work was carried out and the results were shown by MATLAB. In the training phase, these three methods, (PSO, CSO, and the proposed hybrid PSOCSO)method were applied on the plant leaves images, these methods got to the best classification rate.

The method of defining and assigning the coefficients for each algorithm depends on the type of work and the problem that the researcher is working to find the solution to, in which the specific coefficients may differ according to the type of problem to be solved. For our research, these values for the coefficients of the algorithms applied in our research were determined after the experiment and the appropriate choice for us in the work. For the (PSO) algorithm, (C1, C2) was set at (2), (W) at (0.4) and the population (200) the number of iteration was (300). In the (CSO) algorithm, the 
coefficients $\mathrm{R}=0.35, \mathrm{H}=0.55, \mathrm{C}=0.5$, the value of $\mathrm{G}=3$, and the population number (300) were determined, while the number of cycles was determined by (400). As for the proposed hybrid algorithm (PSO-CSO), the coefficients were set as follows (C1, C2) at (2) and (W) at (0.4), $\mathrm{R}=0.35, \mathrm{H}=0.55, \mathrm{C}=0.5$, and the value $\mathrm{G}=(3)$, the population was (300) and the number of courses was (400).

For the test phase, in the first test, samples of plant leaves for eight plants are apples, cherry, peaches, grapes, potatoes, tomatoes, strawberries, and peppers were used as input data. The system starts using the PSO algorithm classifier and showing its classification rate $(94.2 \%)$ percent, then using the CSO algorithm classifier and demonstrating its classification rate of $(92.8 \%)$ percent. while The proposed method (PSO-CSO hybrid method)showed the best classification ratio (96.9\%) percent. In the second test, samples of plant leaves for tomato and potato plants and leaf blight disease and early blight disease, respectively are used. Classification employed the PSO algorithm classifier, which demonstrated its effectiveness with a (95.8\%) percent classification rate. Using the CSO algorithm classifier and demonstrating its accuracy showed a ratio of $(94.6 \%)$ percent and the proposed algorithm improved the detection classification rate of $(98.18 \%)$.

Figure (8) represents the main interface of the proposed system. Table (1) shows the numbers of each plant category in the first test, which consists of eight different types of plants with the classification ratio of normal and diseased leaves. Figure (9) shows through the Matlab screen the results of the first test phase For the proposed hybrid method (PSO-CSO) for each of the classes in the first test, which consisted of eight different types of plants. In Table (2) the numbers of each plant category in the test show the plants in the second test consisting of tomato and potato plants with leaf blight and early blight common between them with the classification ratio of normal and diseased leaves. Figure (10) shows through the Matlab screen as well the results The second test phase of the proposed hybrid method (PSO-CSO) for each of the classes consisting of tomato and potato plants with leaf blight and early blight common between them. In Table (3) shows the average rating ratio for the first test of the (PSO) and (CSO) algorithms and the proposed hybrid method. (PSO -CSO) Table (4) shows the average rating ratio for the second test also using (PSO) and (CSO) algorithms and the proposed hybrid method (PSO -CSO). Table (5) includes a comparison between the results of the proposed hybrid method (PSO-CSO) and the results of some researchers in the same field.

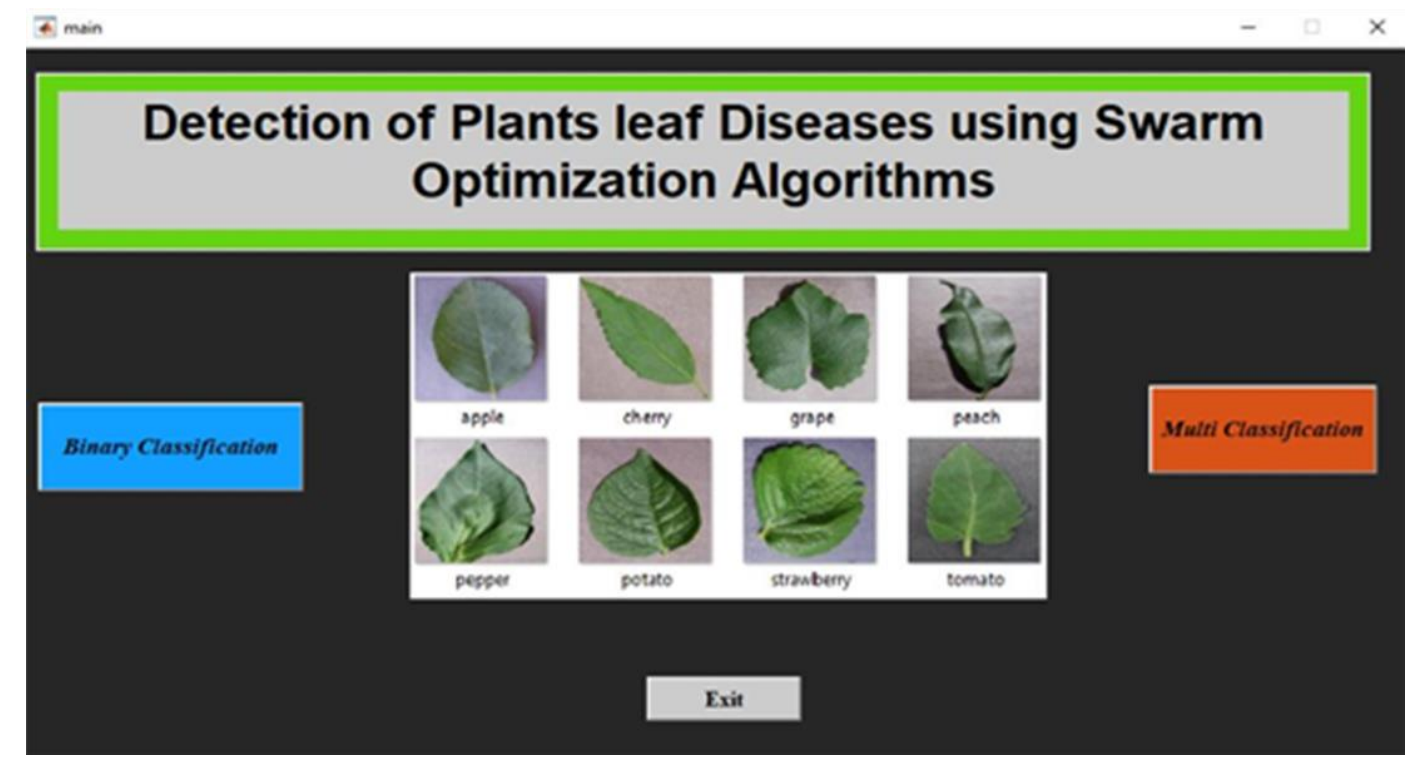

Figure 8. The main interface of the proposed system 
Table 1. Preparing each of the plant categories in the first test with the classification ratio of

\begin{tabular}{|c|c|c|}
\hline \multicolumn{3}{|c|}{ normal and diseased leaves. } \\
\hline class & $\begin{array}{l}\text { Total number of image } \\
\text { for the testing }\end{array}$ & $\begin{array}{l}\text { The number of images is } \\
\text { incorrectly categorized }\end{array}$ \\
\hline Healthy Apple & 14 & 14 \\
\hline diseased Apple & 11 & 11 \\
\hline Healthy Cherry & 10 & 10 \\
\hline diseased Cherry & 14 & 13 \\
\hline Healthy Grape & 15 & 15 \\
\hline diseased Grape & 16 & 15 \\
\hline Healthy Peach & 17 & 17 \\
\hline diseased Peach & 17 & 17 \\
\hline Healthy Pepper & 12 & 12 \\
\hline diseased Pepper & 11 & 10 \\
\hline Healthy Potato & 10 & 9 \\
\hline diseased Potato & 11 & 11 \\
\hline Healthy Strawberry & 15 & 14 \\
\hline diseased Strawberry & 17 & 16 \\
\hline Healthy Tomato & 18 & 18 \\
\hline diseased Tomato & 17 & 16 \\
\hline \multicolumn{2}{|c|}{ Healthy detection Accuracy rate } & $\% 98.1982$ \\
\hline \multicolumn{2}{|c|}{ Disease detection Accuracy rate } & $\% 95.614$ \\
\hline \multicolumn{2}{|c|}{ Average ratio } & $\% 96.9$ \\
\hline
\end{tabular}

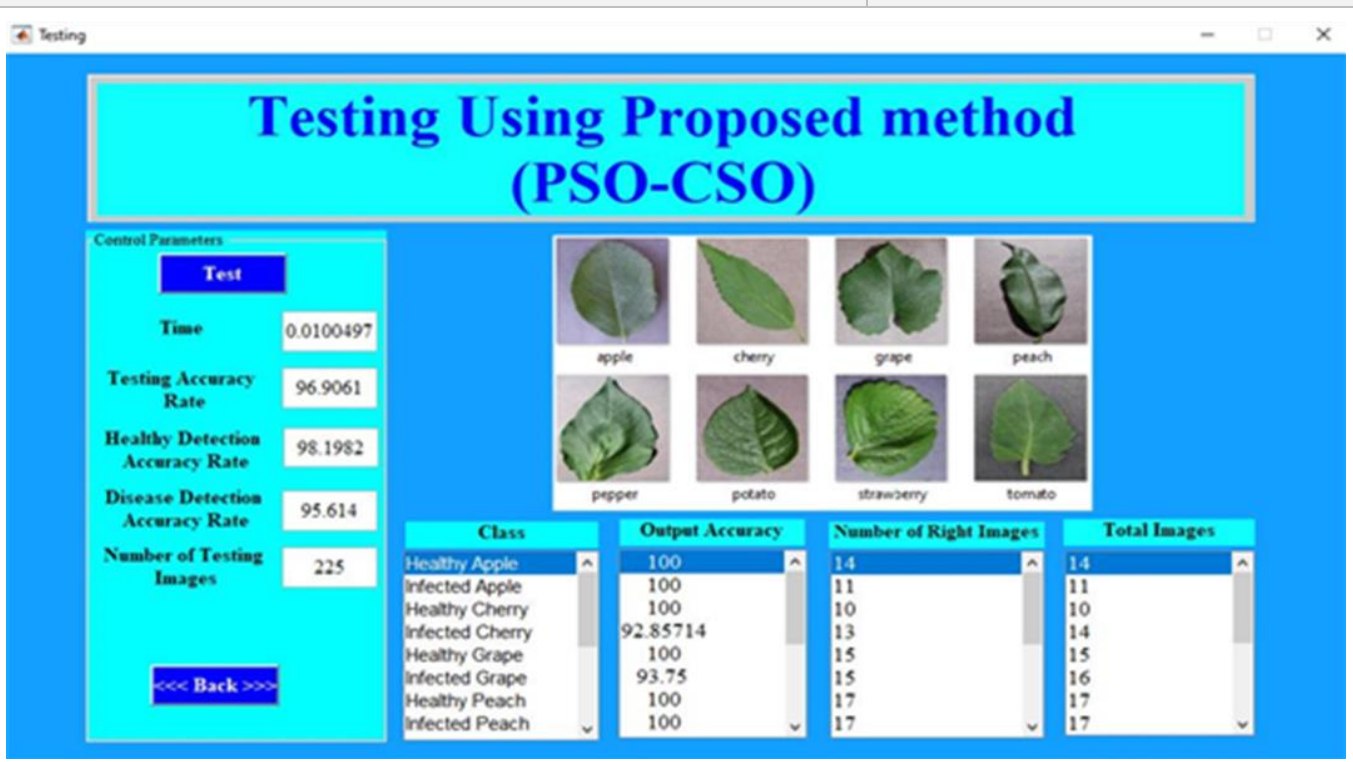

Figure 9. The results of the process of classification results for each category in the first test using the proposed hybrid method through the Matlab program screen.. 
Table 2. Preparing each of the plant categories in the second test with the classification ratio of normal and diseased leaves.

\begin{tabular}{|c|c|c|}
\hline class & $\begin{array}{c}\text { Total number of image for } \\
\text { the testing }\end{array}$ & $\begin{array}{c}\text { The number of images is } \\
\text { incorrectly categorized }\end{array}$ \\
\hline Potato Early Blight & 24 & 24 \\
\hline Potato Late Blight & 21 & 21 \\
\hline Potato Healthy & 14 & 13 \\
\hline Tomato Early Blight & 20 & 20 \\
\hline Tomato Late Blight & 19 & 18 \\
\hline Tomato Healthy & 27 & 27 \\
\hline Healthy detection Accuracy rate & $\% 97.561$ \\
\hline Disease detection Accuracy rate & $\% 98.18$ \\
\hline \multicolumn{2}{|r|}{ Average ratio } \\
\hline
\end{tabular}

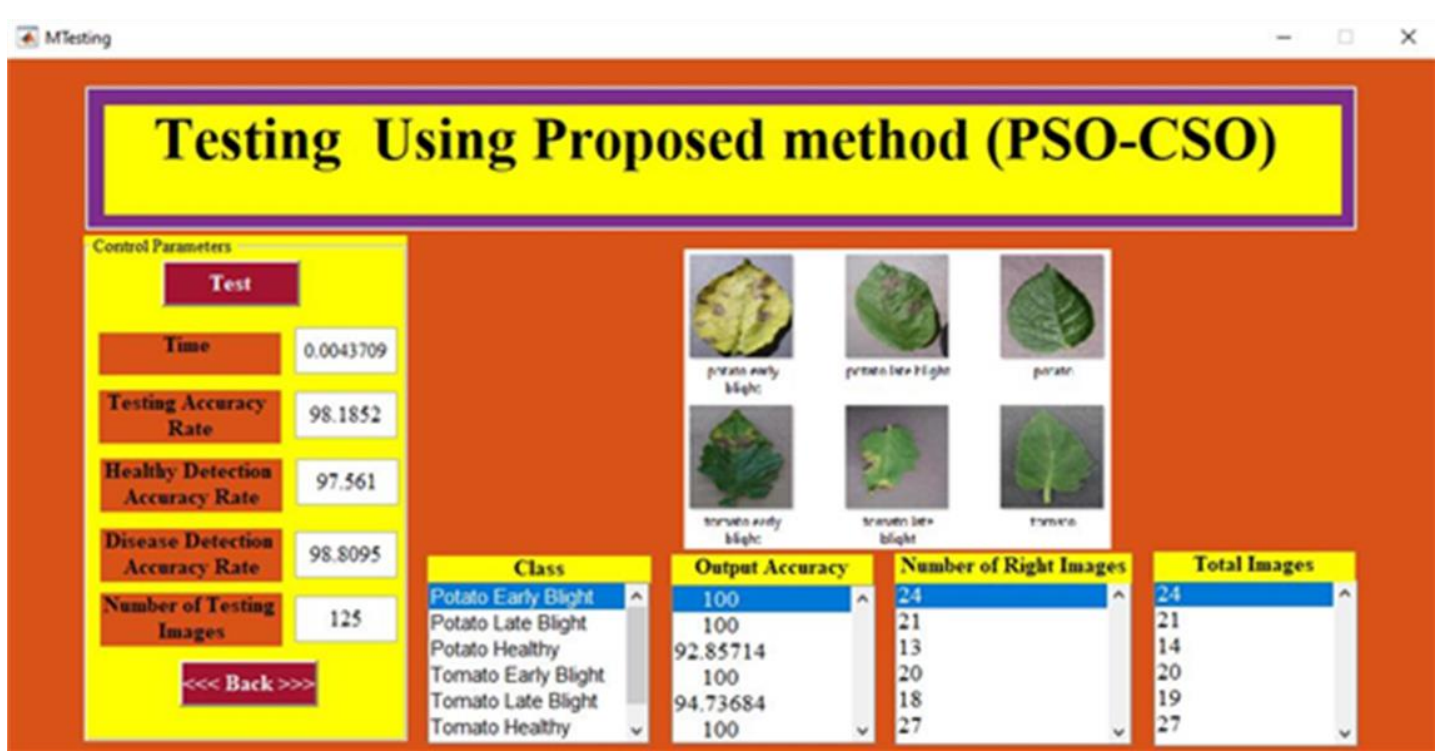

Figure 10. The results of the classification results process for each category in the second test using the proposed hybrid method through the Matlab program screen.

Table.3.Results of the testing process for the first test images of eight plants using algorithms PSO, CSO, and Proposed hybrid method (PSO -CSO).

\begin{tabular}{|c|c|c|}
\hline Methods & $\begin{array}{c}\text { No of images } \\
\text { taken for testing }\end{array}$ & $\begin{array}{c}\text { Classification } \\
\text { rate }\end{array}$ \\
\hline PSO & 225 & $\% 94.2$ \\
\hline CSO & 225 & $\% 92.8$ \\
\hline $\begin{array}{c}\text { Proposed hybrid method (PSO - } \\
\text { CSO) }\end{array}$ & 225 & $\% 96.9$ \\
\hline
\end{tabular}


Table.4.Results of the testing process for the second test images of tomato and potato using algorithms PSO and CSO, and Proposed method (PSO -CSO).

\begin{tabular}{|c|c|c|}
\hline Methods & $\begin{array}{c}\text { No of images } \\
\text { taken for testing }\end{array}$ & $\begin{array}{c}\text { Classification } \\
\text { rate }\end{array}$ \\
\hline PSO & 125 & $\% 95.8$ \\
\hline CSO & 125 & $\% 94.6$ \\
\hline $\begin{array}{c}\text { Proposed hybrid method (PSO - } \\
\text { CSO) }\end{array}$ & 125 & $\% 98.18$ \\
\hline
\end{tabular}

Table 5. Comparison between the results of the proposed hybrid method (PSO-CSO) and the results of some researchers in the same field..

\begin{tabular}{|c|c|c|c|c|c|}
\hline & Search Name & researcher name & The method used & $\begin{array}{l}\text { the } \\
\text { year }\end{array}$ & $\begin{array}{c}\text { Accuracy } \\
\text { ratio }\end{array}$ \\
\hline 1 & $\begin{array}{c}\text { A PSO model for } \\
\text { disease pattern detection } \\
\text { on leaf surfaces[6] }\end{array}$ & $\begin{array}{c}\text { Kanthan } \\
\text { Muthukannan and } \\
\text { Pitchai Latha }\end{array}$ & $\begin{array}{c}\text { Particle swarm } \\
\text { optimization and } \\
\text { HFE ( Hybrid } \\
\text { Feature Extraction } \\
\text { ) }\end{array}$ & 2015 & $\% 90$ \\
\hline 2 & $\begin{array}{c}\text { Plant disease } \\
\text { identification: a } \\
\text { comparative study[9] }\end{array}$ & $\begin{array}{c}\text { Shriroop C. } \\
\text { Madiwalar \& } \\
\text { Medha V. } \\
\text { Wyawahare }\end{array}$ & $\begin{array}{l}\text { YcbCr color-based } \\
\text { segmentation } \\
\text { And SVM } \\
\text { Minimum Distance } \\
\text { Classifier (MDC) }\end{array}$ & 2017 & $83.34 \%$ \\
\hline 3 & $\begin{array}{c}\text { Plant disease } \\
\text { identification and } \\
\text { classification using } \\
\text { back-propagation neural } \\
\text { network with particle } \\
\text { swarm optimization[4] }\end{array}$ & $\begin{array}{l}\text { Moumita chanda \& } \\
\text { Mantosh Biswas. }\end{array}$ & $\begin{array}{c}\text { Back Propagation } \\
\text { Algorithm and } \\
\text { Particle swarm } \\
\text { optimization }\end{array}$ & 2019 & $96.72 \%$ \\
\hline 4 & $\begin{array}{l}\text { Sunflower leaf diseases } \\
\text { detection using image } \\
\text { segmentation based on } \\
\text { particle swarm } \\
\text { optimization[10] }\end{array}$ & Vijai Singh & $\begin{array}{c}\text { Particle swarm } \\
\text { optimization(pso) }\end{array}$ & 2019 & $\% 98$ \\
\hline 5 & $\begin{array}{c}\text { An Efficient } \\
\text { classification model for } \\
\text { the } \\
\text { plant disease detection } \\
{[12]}\end{array}$ & $\begin{array}{c}\text { SiriSumanKalavala, } \\
\text { and } \\
\text { SrideviSakhmuri,\& } \\
\text { B B V } \\
\text { Satyavaraprasad }\end{array}$ & $\begin{array}{l}\text { SVM } \\
\text { (GUI) }\end{array}$ & 2019 & $90 \%$ \\
\hline
\end{tabular}




\begin{tabular}{|c|c|c|c|c|c|}
\hline 6 & $\begin{array}{c}\text { A particle swarm } \\
\text { optimization based } \\
\text { for vegetable ensemble } \\
\text { crop disease } \\
\text { recognition[11] }\end{array}$ & $\begin{array}{c}\text { Archana Chaudhary } \\
\text { and Ramesh Thakur } \\
\text { \& Savita Kolhe \& } \\
\text { Raj Kamal }\end{array}$ & $\begin{array}{c}\text { EnsPSO } \\
\text { (Ensemble Particle } \\
\text { Swarm } \\
\text { Optimization) } \\
\text { Includes } \\
\text { Vote selection } \\
\text { method } \\
\text { Naive Bayse } \\
\text { Algorithm } \\
\text { CFS (Correlation } \\
\text { based Feature } \\
\text { Selection),and } \\
\text { Particle swarm } \\
\text { optimization(pso) }\end{array}$ & 2020 & $\% 96$ \\
\hline
\end{tabular}

\subsection{Conclusions}

The experimental results showed that the proposed hybrid method (PSO-CSO) was more accurate and better performance compared to (PSO) algorithm and (CSO) algorithm applied in this work. The particle swarm algorithm (PSO), but the (CSO) algorithm was characterized by its stability in performance, which led to working on applying the idea of merging the two algorithms and creating an algorithm that combines the features of the two algorithms to obtain a hybrid algorithm that is more stable and has better performance, which showed that through the results obtained in this work.

In the future, it is possible to work on expanding the database to include a larger number of plant diseases, as well as the possibility of performing merge among other types of optimization algorithms to achieve better results.

\section{Acknowledgments}

We express our thanks and appreciation to the University of Mosul for its persistent support in accomplishing this work. 


\section{REFERENCES}

[1] SK, P. K., Sumithra, M. G., \& Saranya, N.(2019). Particle Swarm Optimization (PSO) with fuzzy c means (PSO-FCM)-based segmentation and machine learning classifier for leaf diseases prediction. Concurrency and Computation: Practice and Experience, e5312.

[2] Chouhan, S. S., Kaul, A., Singh, U. P., \& Jain, S. (2018). Bacterial foraging optimization based radial basis function neural network (BRBFNN) for identification and classification of plant leaf diseases: an automatic approach towards plant pathology. IEEE Access, 6, 8852-8863.

[3] Singh, V., \& Misra, A. K. (2017). Detection of plant leaf diseases using image segmentation and soft computing techniques. Information processing in Agriculture, 4(1), 41-49.

[4] Chanda, M., \& Biswas, M. (2019, April). Plant disease identification and classification using back-propagation neural network with particle swarm optimization. In 2019 3rd International Conference on Trends in Electronics and Informatics (ICOEI) (pp. 1029-1036). IEEE.

[5] Andrushia, A. D., \& Patricia, A. T. (2020). Artificial bee colony optimization (ABC) for grape leaves disease detection. Evolving Systems, 11(1), 105-117.

[6] Muthukannan, K., \& Latha, P. (2015). A PSO model for disease pattern detection on leaf surfaces. Image Analysis \& Stereology, 34(3), 209-216.

[7] Francis, J., \& Anoop, B. K. (2016, March). Identification of leaf diseases in pepper plants using soft computing techniques. In 2016 conference on emerging devices and smart systems (ICEDSS) (pp. 168-173). IEEE.

[8] Prakash, R. M., Saraswathy, G. P., Ramalakshmi, G., Mangaleswari, K. H., \& Kaviya, T. (2017, March). Detection of leaf diseases and classification using digital image processing. In 2017 international conference on innovations in information, embedded and communication systems (ICIIECS) (pp. 1-4). IEEE.

[9] Madiwalar, S. C., \& Wyawahare, M. V. (2017, February). Plant disease identification: a comparative study. In 2017 International Conference on Data Management, Analytics and Innovation (ICDMAI) (pp. 13-18). IEEE.

[10] Singh, V. (2019). Sunflower leaf diseases detection using image segmentation based on particle swarm optimization. Artificial Intelligence in Agriculture, 3, 6268.

[11] Kalavala, s., \& Sakhmuri, s, Prasad, B.S. (2019). An Efficient classification model for the plant disease detection:. IJITEE, ISSN:2278-3075, Volume-8, Issue-7, May 2019.

[12] Chaudhary, A., Thakur, R., Kolhe, S., \& Kamal, R. (2020). A particle swarm optimization based ensemble for vegetable crop disease recognition. Computers and Electronics in Agriculture, 178, 105747.

[13] Mutlag, W. K., Ali, S. K., Aydam, Z. M., \& Taher, B. H. (2020, July). Feature Extraction Methods: A Review. In Journal of Physics: Conference Series (Vol. 1591, No. 1, p. 012028). IOP Publishing. 
[14] Kumar, G. P., Gangarao, B., Kotha, N. S., \& Lova, R. (2011). Isolation and evaluation of tamarind seed polysaccharide being used as a polymer in pharmaceutical dosage forms. Research Journal of Pharmaceutical, Biological and Chemical Sciences, 2(2), 274-290.

[15] Kour, V. P., \& Arora, S. (2019). Particle swarm optimization based support vector machine (P-SVM) for the segmentation and classification of plants. IEEE Access, 7, 29374-29385.

[16] Shuaibu, M., Lee, W. S., Hong, Y. K., \& Kim, S. (2017). Detection of apple marssonina blotch disease using particle swarm optimization. Transactions of the ASABE, 60(2), 303-312.

[17] Anam, S. (2020, June). Segmentation of Leaf Spots Disease in Apple Plants Using Particle Swarm Optimization and K-means Algorithm. In Journal of Physics: Conference Series (Vol. 1562, No. 1, p. 012011). IOP Publishing.

[18] Bharanidharan, N., \& Rajaguru, H. (2020). Improved chicken swarm optimization to classify dementia MRI images using a novel controlled randomness optimization algorithm. International Journal of Imaging Systems and Technology, 30(3), 605-620.

[19] Wu, D., Kong, F., Gao, W., Shen, Y., \& Ji, Z. (2015, June). Improved chicken swarm optimization. In 2015 IEEE international conference on cyber technology in automation, control, and intelligent systems (CYBER) (pp. 681686). IEEE.

[20] Meng, X., Liu, Y., Gao, X., \& Zhang, H. (2014, October). A new bio-inspired algorithm: chicken swarm optimization. In International conference in swarm intelligence (pp. 86-94). Springer, Cham.

[21] Liang, J., Wang, L., Ma, M., \& Zhang, J. (2018). A fast SAR image segmentation method based on improved chicken swarm optimization algorithm. Multimedia Tools and Applications, 77(24), 31787-31805.

[22] Hafez, A. I., Zawbaa, H. M., Emary, E., Mahmoud, H. A., \& Hassanien, A. E. (2015, November). An innovative approach for feature selection based on chicken swarm optimization. In 2015 7th international conference of soft computing and pattern recognition (SoCPaR) (pp. 19-24). IEEE.

[23] Wu, Y., Yan, B., \& Qu, X. (2018). Improved chicken swarm optimization method for reentry trajectory optimization. Mathematical Problems in Engineering, 2018.

[24] Deb, S., Gao, X. Z., Tammi, K., Kalita, K., \& Mahanta, P. (2019). Recent studies on chicken swarm optimization algorithm: a review (20142018). Artificial Intelligence Review, 1-29 